L. Procter and Miss S. Singer. Financial assistance from the Manchester Regional Hospital Board is acknowledged with thanks.

\section{REFERENCES}

Ahlquist, K. A. (1967). Proc. Ass. clin. Brochem., 4, 220.

Atkins, H. (1966). Ann. Roy. coll. Surg. Engl., 38, 133.

Bulbrook, R. D. (1965). Vitam. and Horm., 23, 329.

(1966). In Clinical Evaluation in Breast Cancer, edited by J. L. Hayward and R. D. Bulbrook, p. 78. London.

Greenwood, F. C. Band Hayward, J. L. (1960). Lancet, 1, 1154

and Hayward, J. L. (1966). In Androgens in Normal and Pathological Conditions, edited by A. Vermeulen and D. Exley, p. 101 Amsterdam.

- Spicer, C. C., and Thomas, B. S. (1962). Ibid., 2, 1238.

- and Thomas, B. S. (1964). Ibid., 1, 945.

Deshpande, N., Jenscn, V., Bulbrook, R. D., and Doouss, T. W. (1967). Steroids, 9,393 .
Few, J. D. (1961). 7. Endocr., 22, 31.

James, V. H. T., and De Jong, M. (1961). 7. clin. Path., 14, 425

Juret, P., Hayem, M., and Flaisler. A. (1964). J. Chir. (Paris), 87, 409 Kumaoka, S., Abe, A., Sakauchi, N., Takatani, O., and Kusama M (1966). Abstracts of 9th International Cancer Congress, Tokyo, (1966). Abstracts

Miller, H., Durant, J. A., Jacobs, A. G., and Allison, J. F. (1967). Brit. med. 7., 1, 147.

Paterson, R., and Russeli, M. H. (1959a). F. Fac. Radiol. (Lond.), 10, 175.

(1959b). Ibid., 10, 130.

Stempfel, R. S., jun., Sidbury, J. B., iun., and Migeon, C. J. (1960). f. clin. Endocr., 20, 814

Thomas, B. S., and Bulbrook, R. D. (1966). In Androgens in Normal and Pathological Conditions, edited by $\mathrm{A}$. Vermeulen and D. Exley, p. 49. Amsterdam.

Wilson, R and Hayward, J. L. (1967). Brit. med. 7., 3, 523. Emerson, K., and Moore, F., D. (1967), J., Bmer med Ass. 199., 474.

\title{
Rubella : a Method for Rapid Diagnosis of a Recent Infection by Demonstration of the IgM Antibodies
}

\author{
TIMO VESIKARI,* C.M.; ANTTI VAHERI, M.D.
}

Brit. med. F., 1968, 1, 221-223

Specific virological diagnosis of rubella is particularly important in pregnant women with a view to possible therapeutic abortion. This can be effectively done by using haemagglutinationinhibition (H.I.) or complement-fixation techniques, provided a serum pair taken in the acute and convalescent phases of the infection is available. However, as pointed out by Halonen et al. (1968), there always remain a certain number of rubella infections in which the first serum sample was taken too late to demonstrate any rise in antibody titre. Moreover, in pregnancies at the end of the third month even a week's delay ought to be avoided, because the therapeutic abortion should be applied for and executed as soon as possible. In these cases we should be able to distinguish a recent antibody response from previous experience with rubella. This cannot be concluded from the level of the H.I. titre alone, because there are individual variations in the response and because the titre seems to remain at a high value for a long time. Combination of the complementfixation method with crude complement-fixation antigen and the H.I. technique apparently does not provide any solution to this problem.

Earlier studies (Schluederberg, 1965) have demonstrated how the amount of $\operatorname{IgM}$ and $\operatorname{IgG}$ immune globulins varies in the course of viral infections. An initial production of $\operatorname{IgM}$ and subsequent IgG neutralizing rubella antibody was demonstrated previously in rubella-infected infants (Bellanti et al., 1965). The present paper reports the relative quantities of $\operatorname{IgM}$ and $\operatorname{IgG}$ H.I. antibodies in postnatal rubella infection, and describes a routine method for the diagnosis of rubella in which a single serum sample is used.

\section{Materials and Methods}

Treatment of Serum Samples.-Ordinarily $0.2 \mathrm{ml}$. of $1: 5$ dilution of untreated serum was used in the sedimentation analysis. In a few cases $0.1 \mathrm{ml}$. of undiluted serum was used in an attempt to demonstrate slight amounts of $\operatorname{IgM}$ antibody. To test the effect of kaolin some sera were treated as described in the rubella H.I. method of Stewart et al. (1967). To demon-

- University Department of Virology, and Virus Laboratory, Orion, Helsinki, Finland. strate sulphydryl reactivity treatment with $0.1 \mathrm{M}$ 2-mercaptoethanol for two hours at $37^{\circ} \mathrm{C}$. plus overnight dialysis against Dulbecco's phosphate buffered saline at $4^{\circ} \mathrm{C}$. was given. Both treatments resulted in a 1:5 dilution of the serum, and subsequently $0.2 \mathrm{ml}$. was analysed.

Sedimentation Analysis.-The samples were layered on top of linear $37-12.5 \% \mathrm{w} / \mathrm{v}$ sucrose gradients in phosphate-buffered saline (Vaerman et al., 1963) and centrifuged in a Spinco SW 39 rotor at 35,000 r.p.m. for $14 \frac{1}{2}$ hours. Twelve to 14 fractions were collected dropwise through the bottom of the tubes. The linearity of the gradients was checked by means of an Abbe refractometer.

Titration.-The original rubella H.I. method was employed (Stewart et al., 1967). The antigen was prepared in rubellainfected BHK 21/13 S suspension cultures (Vaheri et al., 1965) by treatment of the tissue culture fluid with Tween 80 and ether (Halonen et al., 1967). The H.I. titres varied between $1: 8$ and $1: 64$. The titrations were carried out on microtitre $\mathrm{V}$-plates with the use of a multimicrodiluter handle.

\section{Results}

Development of Antibody Response Pattern.-Five rubella cases in schoolchildren aged 10 were followed by serum samples taken at intervals after the onset of infection. (The total H.I. titres ranged at one week from $1: 160$ to $1: 640$, at three weeks from $1: 640$ to $1: 2,560$, and at six weeks from $1: 640$ to 1 : 2,560.) At one week (Fig. 1 A) a noticeable amount of IgM antibody was detected in all cases as well as IgG antibody. The relative quantity of IgG antibody was, however, always greater than that of IgM type. Three weeks after the rash the IgM antibody was still measurable in four out of five cases (Fig. 1 B). The fifth sample can apparently be regarded as an example of a weak IgM response, since such early disappearance of IgM immune globulin has not been found in any other rubella case studied so far. Six weeks after the rash there was no detectable amount of IgM in any serum (Fig. 1 C). In several other rubella cases with significant rise (fourfold) in total H.I. titre IgM antibody was constantly demonstrated in a serum sample obtained one to two weeks after the rash. 
In a case of rubella encephalitis where repeated serum samples were taken, the IgM antibody was demonstrable on the fifth day and the response pattern resembled closely that described above. It was not possible to demonstrate any rise in the IgM antibody titre between 5 and 20 days after the rash.
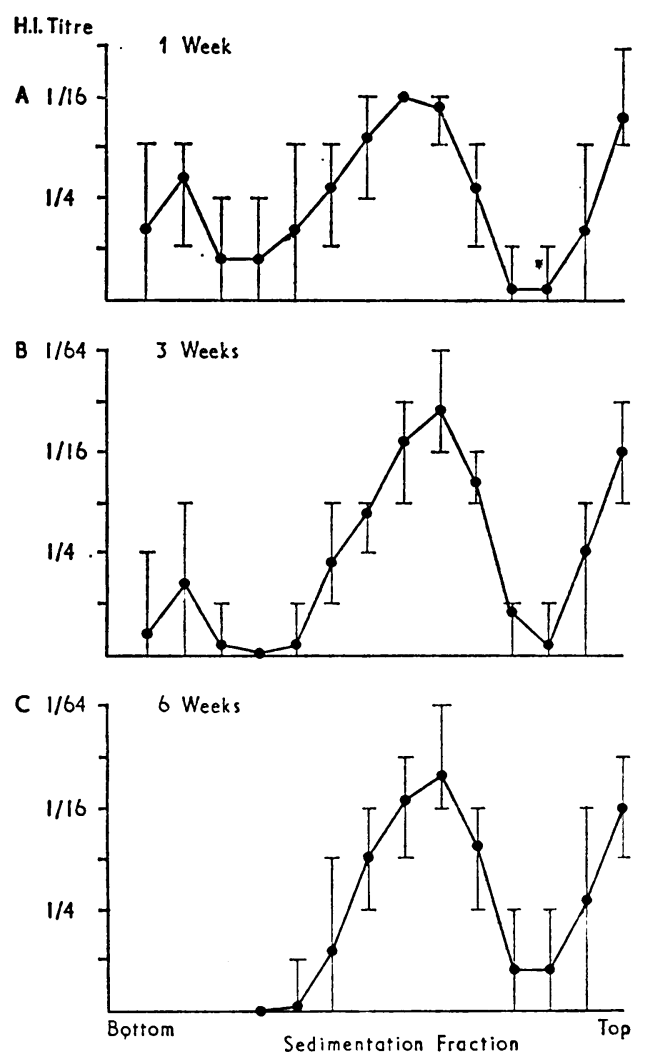

FIG. 1.-Sedimentation analyses of H.I. antibodies in five cases of rubella infection. Geometric mean and range of titres (A) 1 week, (B) 3 weeks, and (C) 6 weeks after onset of rash.

Application of Test to Clinical Problem Cases.-In the routine serological service of our laboratory 13 cases of suspected rubella in pregnancy were seen where the first serum sample had been taken five or more days after onset of the disease. All these sera had a positive rubella H.I. titre (see Table). IgM

List of Problem Cases of Pregnant Women with Recent Rubella-like Problem Cases of Pregnant Wucrose Gradient Method

\begin{tabular}{|c|c|c|c|c|}
\hline Case No. & $\begin{array}{c}\text { First } \\
\text { Sample } \\
\text { Day* }\end{array}$ & $\begin{array}{l}\text { Total } \\
\text { H.I.: } \\
\text { titre }\end{array}$ & $\begin{array}{c}\text { IgM } \\
\text { Demonstrable } \\
\text { in First Sample }\end{array}$ & $\begin{array}{c}\text { H.I.-titre } \\
\text { in a Later } \\
\text { Sample† }\end{array}$ \\
\hline $\begin{array}{r}1 \\
2 \\
3 \\
4 \\
5 \\
6 \\
7 \\
8 \\
9 \\
10 \\
11 \\
12 \\
13\end{array}$ & 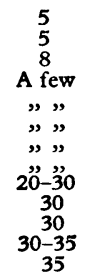 & $\begin{array}{lll}1 & : 80 \\
1 & 320 \\
1 & 5,120 \\
1 & 1,280 \\
1 & 320 \\
1 & 160 \\
1 & 320 \\
1 & 80 \\
1 & 1,280 \\
1 & 160 \\
1 & 320 \\
1 & 1,280 \\
1 & 160\end{array}$ & $\begin{array}{l} \pm \\
\pm \\
\pm \\
\pm \\
\pm \\
= \\
= \\
\pm \\
\pm\end{array}$ & 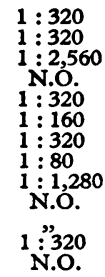 \\
\hline
\end{tabular}

Days after onset of the rubella-like disease.
t Later sample usually obtained one to two weeks after the first one. In Case 7 the second sample was obtained two months later.

antibody was found in five sera, and consequently the uncertain or lacking clinical diagnosis could be confirmed. One of these women (Case 12) had a history longer than one month, though the actual date of the rash could not be stated. In the rest of the cases only IgG antibody was found, suggesting earlier rubella infection. It should be noted here that in many of these problem cases the history of a rubella-like disease was not based on a physician's examination but on the patient's own statements. Naturally in cases diagnosed by a physician a serum sample was usually obtained in the acute phase so that it was still possible to demonstrate a rise in the total H.I. titre.

Non-specific Inhibition.-All tested serum samples contained a considerable amount of non-specific haemagglutination inhibitor, which always remained at the top of the sucrose gradient and thus could readily be separated from the IgG and IgM antibodies. The non-specific inhibitor was entirely rernoved by kaolin treatment, which had little or no effect on IgM and IgG antibody titre (Fig. $2 \mathrm{~A}$ and $\mathrm{B}$ ).
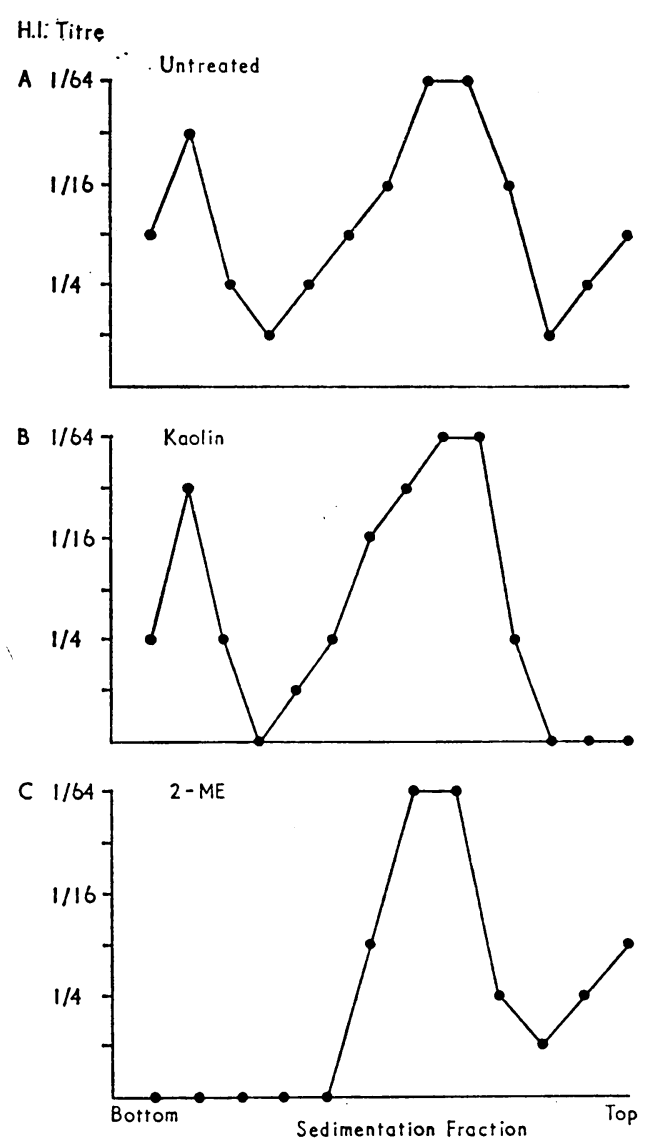

FIG. 2.-Case 3. Sedimentation analysis of H.I. activity in a serum collected eight days after the onset of rubella rash (A) untreated, (B) treated with kaolin, and (C) treated with 2-mercaptoethanol.

Effect of 2-Mercaptoethanol.-Treatment with 2-mercaptoethanol removed the IgM activity completely, but did not affect the IgG titre (Fig. $2 \mathrm{C}$ ). This removal of the relatively small amount of IgM antibody had only a slight effect on the total H.I. titre of the serum sample, which could not be reliably measured by the twofold dilution techniques.

\section{Discussion}

After the rash of a rubella infection there apparently is a latent period of four to five days during which rubella antibodies can only infrequently be demonstrated by H.I. or other techniques (Halonen et al., 1968). The antibody titre then rises very rapidly to the maximum level. Occasionally a serum sample is obtained during the growing phase of antibody production, the regular serum pair consisting of a negative one and one of very high titre. Thus if the taking of a blood sample is missed in the first week after the rash it is not usually possible to show any rise in the rubella H.I. titre, or at least it will be difficult to evaluate how great a rise can be regarded as significant. In these cases the demonstration of IgM anti- 
body by the present method may prove a useful aid in the diagnosis of rubella up to three to four weeks after the infection.

Greater accuracy and better reproducibility in titrating the fractions are naturally obtained by using the conservative tube dilution method, with either twofold or 1.5-fold dilutions. With regard to the rapidity and simplicity of the microtitre system with a multimicrodiluter handle, the results seemed to be satisfactory for a routine diagnostic procedure.

It remains to be established whether the immune globulin response is different in the hypothetical case of rubella reinfection, the sole IgG type of response being a considerable limitation for the usefulness of the described method. So far, in each early convalescent rubella serum studied we have been able to demonstrate at least a small amount of IgM antibody. Rubella vaccination experiments will presumably offer a chance of studying this problem.

During the preparation of this paper Banatvala et al. (1967) reported a method for the diagnosis of recent rubella infection by using 2 -mercaptoethanol treatment with subsequent parallel titration of the treated and untreated serum samples. In 17 early convalescent sera studied they demonstrated a fourfold reduction in three cases, a twofold reduction in 10 cases, and no H.I. titre reduction in four cases. It has been our experience that with regard to the reproducibility of the rubella H.I. test a twofold difference can hardly be regarded as significant. Thus in the acute phase with a positive H.I. titre the 2mercaptoethanol method may prove useful. However, at least in delayed cases with early convalescent phase sera, the present method probably gives more reliable results.

\section{Summary}

Rubella IgM antibody with haemagglutination-inhibiting activity was regularly demonstrated in early convalescent sera by sedimentation analysis in sucrose gradients. This provided a method of serological diagnosis of recent rubella infection in cases where the first blood sample was delayed and no rise in total antibody titre could be demonstrated. The gradient centrifugation method was employed in 13 problem cases of pregnant women with a history of a recent rubella-like disease, and IgM antibody was found in five of these.

This investigation was supported by grants from the Sigrid Jusélius Foundation and from the Finnish Medical Research Council.

\section{REFERENCES}

Banatzala, J. E., Best, J. M., Kennedy, E. A., Smith, E. E., and Spence, M. E. (1967). Brit. med. 7., 3, 285.

Bellanti, J. A. Artenstein, M. S., Olson, L. C. Buescher, E. L., Luhrs, C. E., and Milstead, K. L. (1965). Amer. 尹. Dis. Child., 110, 464.

Halonen, P. E., Stewart, J. A., and Hall, A. D. (1967). Ann. Med. exp. Fenn., 45, 182.

- et al. (1968). To be published.

Schluederberg, A. (1965). Nature (Lond.), 205, 1232.

Stewart, G. L., Parkman, P. D., Hopps, H. E., Douglas, R. D., Hamilton, J. P., and Meyer. H. M. (1967). New Engl. Ұ. Med., 276, 554.

Vaerman, J.-P., Heremans, J. F., and Vacrman, C. (1963). F. Immunol., 91, 7.

Vaheri, A., Sedwick, W. D., Plotkin, S. A., and Maes, R. (1965). Viro$\log y, 27,239$

\section{Medical Memoranda}

\section{Suppurative Pericarditis Complicating Myocardial Infarction}

\section{Brit. med. F., 1968, 1, 223-224}

Pericarditis may complicate myocardial infarction under a variety of circumstances, but when suppuration occurs the outcome is usually fatal (Katz, 1964 ; Horeau et al., 1966 ; Korns, 1966). The case history of a patient who survived this serious complication and was alive and well 18 months later is described.

\section{CASe History}

The patient, a medical practitioner aged 62 , was admitted to hospital on 23 January 1966 after two attacks of prolonged cardiac pain. He had a fever of $102^{\circ} \mathrm{F}$. $\left(38.9^{\circ} \mathrm{C}\right.$.), a tachycardia of 110 per minute, and a blood pressure of $180 / 110 \mathrm{~mm}$. Hg. The electrocardiogram (Fig. 1 A) suggested a recent transmural infero-lateral myocardial infarction. The E.S.R. was $41 \mathrm{~mm}$./hour, the leucocyte count 11,200/cu. mm., the S.G.O.T. 118 units $/ 100 \mathrm{ml}$., and the serum cholesterol $170 \mathrm{mg} . / 100 \mathrm{ml}$. Chest $x$-ray examination showed a slightly enlarged heart with pulmonary venous congestion. He was treated with amylobarbitone, morphine, intravenous heparin, and phenindione.

On 27 January he developed bruising in each arm and had a brief epistaxis. The prothrombin ratio was $2.7: 1$ (patient: control), and anticoagulant therapy was temporarily withdrawn. Transient pericardial and pleural friction rubs were heard, but the pyrexia settled, the bruising resolved, and his general condition improved progressively. He was mobilized and discharged home one month after admission.

He was readmitted on 5 March with sharp central chest pain; he was pale, cold, and clammy but had no fever. The jugular venous pressure was raised $10 \mathrm{~cm}$., the blood pressure had fallen to $80 / 60 \mathrm{~mm} . \mathrm{Hg}$, and a generalized pericardial friction rub could be heard. The electrocardiogram (Fig. 1 B) showed nodal rhythm with concave ST elevation in V1 to V4, and a chest $x$-ray film showed an opacity at the right lung base. The leucocyte count had risen to $28,000 / \mathrm{cu}$. mm., the E.S.R. to $112 \mathrm{~mm}$./hour, the blood urea to $183 \mathrm{mg} . / 100 \mathrm{ml}$., but the S.G.O.T. was 32 units $/ 100 \mathrm{ml}$. He was treated with digoxin, diuretics, and intramuscular penicillin, but paroxysms of nodal tachycardia and prolonged hypotension developed. Prednisone $30 \mathrm{mg}$. daily was started, but when after one week no objective improvement had resulted it was withdrawn.

The venous pressure rose progressively and he developed increasing oedema of the lower limbs, ascites, and, later, a pulsus paradoxus. Chest $x$-ray examination showed increasing cardiac diameter, and fluoroscopy suggested a pericardial effusion. On 1 April 750 ml. of purulent fluid was aspirated from the pericardial cavity; from this fluid a moderate growth of penicillin-resistant Staphylococcus pyogenes was cultured. Penicillin was discontinued and be was treated with oral cloxacillin for the next month. However, on 10 April a further $700 \mathrm{ml}$. of pericardial fluid was aspirated and $500 \mathrm{mg}$. of cloxacillin was instilled into the pericardial cavity. This aspirate cultured a scanty growth of Staph. pyogenes.

Though there was immediate improvement he rapidly relapsed, and five days later operation was undertaken to relieve recurrent tamponade. The pericardium was bulging and tense, and almost 1 litre of thick sterile pus was evacuated. After the operation he improved steadily ; but the electrocardiogram (Fig. $1 \mathrm{C}$ ) showed persistent nodal rhythm with diffuse ST depression and infero-lateral myocardial infarction. He was discharged home on 14 May, and within a few weeks had returned to full activity. Apart from an episode of transient partial heart block further progress was uneventful, and 18 months after discharge he was completely asymptomatic. Physical examination was normal and the electrocardiogram (Fig. 1 D) showed sinus rhythm with an old inferolateral myocardial infarction.

\section{COMMENT}

Suppurative pericarditis was formerly a common terminal event complicating pneumonia and septicaemia, especially in 